\title{
Chemotactic activity of Neisseria gonorrhoeae
}

\author{
ERIC SANDSTRÖM, NIKOS VENIZELOS, AND JAN PALMBLAD \\ From the Departments of Dermatology, Clinical Microbiology, and Medicine IV, Karolinska Institute, \\ Stockholm, Sweden
}

SUMMARY Sonicated whole cells of one of three tested goncoccal strains stimulated neutrophil migration in the agarose gel model. The activity was retained by the material pelleted by highspeed centrifugation of the sonicate. This supports the theory that certain strains possess a cytotaxin bound to the outer membrane.

\section{Introduction}

Opposing views have recently been expressed concerning the capacity of the gonococcus to produce chemotactic factors (cytotaxins) in the absence of complement. ${ }^{12}$ James and Williams, ${ }^{1}$ using the agarose gel method, ${ }^{3}$ found that gonococci could produce cytotaxins in liquid medium but that the response depended on the growth medium and the particular strain used. The chemotactic factor was stable to $100^{\circ} \mathrm{C}$ for 30 minutes. Watt and Medlen, ${ }^{2}$ using Boyden chambers, could not find cytotaxins in the supernatants of 24-hour broth cultures nor in the butanol-acetic extracts of these supernatants. Outer envelope preparations at a concentration of $1 \mathrm{mg} / \mathrm{ml}$ were, however, chemotactic. They concluded that chemotaxis is probably a consequence of an interaction of natural antibodies with the gonococcus causing complement activation.

In the present study we showed that whole gonococci contained chemotactic substances, which are part of high-molecular weight complexes.

\section{Materials and methods}

Strain 15057, an isolate from the male urethra, has been described. ${ }^{4}$ Strain $F 62$ was kindly obtained from Dr T M Buchanan, Seattle, Washington, USA, and strain 5556 was a local isolate from the male urethra.

Gonococci were grown in liquid culture medium according to Wolf-Wat ${ }^{5}$ (proteose peptone No 3 (Difco), $15 \mathrm{~g}$; corn starch, $1 \mathrm{~g} ; \mathrm{K}_{2} \mathrm{HPO}_{4}, 4 \mathrm{~g}$; $\mathrm{KH}_{2} \mathrm{PO}_{4}, 1 \mathrm{~g}$; and $\mathrm{NaCl}, 1 \mathrm{~g}$ to 11 of medium and one ampoule of IsoVitalex and $20 \mathrm{ml} 0.5 \mathrm{~mol} / 1$ $\mathrm{NaHCO}_{3}$ added before use) at $37^{\circ} \mathrm{C}$ on a rotary

Address for reprints: Dr E Sandström, Department of Dermatology, Karolinska Institute, Södersjukhuset, S-100 64 Stockholm, Sweden

Accepted for publication 17 September 1982 shaker until late log phase (about 15 hours) from small inocula of T2 colonies. The cells were harvested at $10000 \times g$ for 15 minutes and washed in PBS; the wet weight was determined and they were frozen at a concentration of $250 \mathrm{mg} / \mathrm{ml}$. The sample was sonicated in 30-second bursts on ice in a 100 W MSE apparatus to more than $95 \%$ lysis. In one experiment the culture fluid was centrifuged at $100000 \times g$ for one hour after precipitation of whole organisms as described above, the pellet washed once in Parker 199 medium, resedimented at $100000 \times \mathrm{g}$, and suspended in Parker 199 medium.

Spontaneous and stimulated neutrophil migration was assessed as described. ${ }^{3}$ Isolated leucocytes $(1 \times$ $10^{4}$ neutrophils $\left./ \mu \mathrm{l}\right)$ which had been washed twice and obtained after dextran sedimentation of erythrocytes were added to a $10 \mu \mathrm{l}$ well in an agarose plate. Opposing this well were two other wells; one contained the different gonococcal preparations or an Escherichia coli supernatant bacterial factor (BF) and the other control media (to assess spontaneous migration).

Statistical analyses were performed with Student's $t$ test.

\section{Results}

The sonicated whole 15057 gonococci (at a concentration of $250 \mathrm{mg} / \mathrm{ml}$ wet weight) were as active as BF as a cytotaxin (figure). Both significantly stimulated neutrophil migration compared with spontaneous migration $(p<0 \cdot 001)$. The culture medium in which the gonococci had been grown, however, exerted a stimulatory effect, which was about half that of the gonococcal preparation. Two different preparations of 15057 were tried and found to be equally active whereas two other strains (F62 and 5556) caused only a migration similar to the medium's (data not shown). The washed pellet, produced by centrifugation at $100000 \times g$ for one 


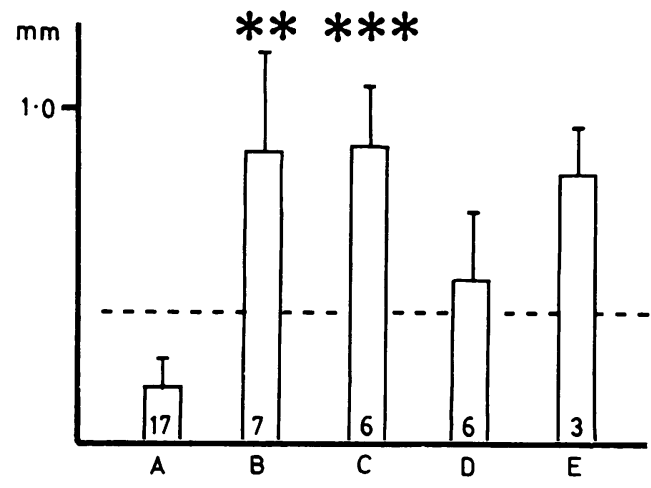

FIGURE Distance to the leading front cells migrating under agarose, either spontaneously $(A)$ or after stimulation with the sonicated whole gonococcal strain $15057(B)$, the bacterial factor (BF) from $E$ coli $(C)$, the culture medium $(D)$, and the washed pellet obtained after centrifugation $(E) .^{* * *}=p<0.001$ and ${ }^{* *}=p<0.01$ when compared with the migration elicited by the medium alone.) The numbers at the bottom of the bars denote the number of experiments. The broken line represents the mean $\pm 2 S D$ limit for spontaneously migrating neutrophilis determined from the analyses of 75 healthy volunteers.

hour and being free from the medium, was also active (figure). This effect was still present after sonication but was lost with further fractionations.

\section{Discussion}

This finding supports those of James and Williams ${ }^{1}$ that certain strains can produce substances capable of stimulating migration of neutrophils. Since the present experiments were performed in the absence of plasma or serum this factor evidently does not belong to the complement system. The finding that the activity could be pelleted from the culture fluid supernatant supports that of Watt and Medlen ${ }^{2}$ that the gonococcal outer envelope also contains active substance. Future research is needed, however, to determine its chemical nature-that is, whether it belongs to those formylated peptides or lipids which have previously been suggested as the main source of bacterial chemotactic factors ${ }^{67}$ Finally, the excretion of the present chemotactic substance by certain gonococcal strains may contribute to the classical gonococcal discharge.

This study was supported by grants from the Karolinska Institute and Osterman's Fund.

We thank Mrs Sonja Koinberg for her skilful technical assistance.

\section{References}

1. James AN, Williams RP. Chemotactic factor(s) of Neisseria gonorrhoeae. Current Microbiology 1978; 1:341-3.

2. Watt PJ, Medlen AR. Generation of chemotaxins by gonococci. In: Brooks GF, Gotschlich EC, Holmes KK, Sawyer WD, Young FE, eds. Immunobiology of Neisseria gonorrhoeae. Washington DC: American Society for Microbiology, $1978 ; 239-41$

3. Palmblad J, Uden A-M, Venizelos $\mathbf{N}$. The quantification of neutrophil orientation and migration under agarose-a new method for detecting directed and random movements. $J$ Immunol Methods 1981;44:37-53.

4. Sandström EG, Danielsson D. Serology of Neisseria gonorrhoeae. Classification by co-agglutination. Acta Pathol Microbiol Scand (B) 1980;88:27-38.

5. Wolf-Watz H, Elmros T, Normark S, Bloom GD. Cell envelope of Neisseria gonorrhoeae. Infect Immun 1975;11: 1332-41.

6. Tainer JA, Turner SR, Lynn WS. New aspects of chemotaxis. Am J Pathol 1975;81:401-10.

7. Schiffmann E, Showell HJ, Corcoran BA, Ward PA, Smith E, Becker EL. The isolation and partial characterization of neutrophil chemotactic factors from $E$ coli. J Immunol 1975; 114: $1831-7$. 